\title{
Gut microbiota regulates neuropathic pain: potential mechanisms and therapeutic strategy
}

\author{
Binbin Lin ${ }^{\dagger}$, Yuting Wang ${ }^{\dagger}$, Piao Zhang ${ }^{\dagger}$, Yanyan Yuan, Ying Zhang and Gang Chen ${ }^{*}$ (D)
}

\begin{abstract}
Neuropathic pain (NP) is a sustained and nonreversible condition characterized by long-term devastating physical and psychological damage. Therefore, it is urgent to identify an effective treatment for NP. Unfortunately, the precise pathogenesis of NP has not been elucidated. Currently, the microbiota-gut-brain axis has drawn increasing attention, and the emerging role of gut microbiota is investigated in numerous diseases including NP. Gut microbiota is considered as a pivotal regulator in immune, neural, endocrine, and metabolic signaling pathways, which participates in forming a complex network to affect the development of NP directly or indirectly. In this review, we conclude the current understanding of preclinical and clinical findings regarding the role of gut microbiota in NP and provide a novel therapeutic method for pain relief by medication and dietary interventions.
\end{abstract}

Keywords: Gut microbiota, Neuropathic pain, Therapeutic strategy

\section{Introduction}

Neuropathic pain is a sustained and nonreversible condition presenting pain as a direct aftereffect of a lesion or disease of the somatosensory system involving peripheral and central levels. It is typically chronic and frequently manifests as persistent or recurrent pain. Hence, the unpleasant feeling induces sleep, fatigue, and emotional disorders, and thereby results in an imbalance of work, leisure life, and family relationships. Epidemiological surveys showed that the prevalence of chronic pain with neuropathic characteristics is approximately $7-10 \%$ [1]. Additionally, $40 \%$ of patients went through some features of NP, referring to a survey of more than 12,000 patients with both nociceptive and NP in Germany [2]. To date, accumulating evidence revealed that the occurrence and development of NP are implicated with peripheral and

\footnotetext{
* Correspondence: chengang120@zju.edu.cn

†Binbin Lin, Yuting Wang and Piao Zhang contributed equally to this work. Department of Anesthesiology, Sir Run Run Shaw Hospital, School of Medicine, Zhejiang University, 3 Qingchun East Road, Zhejiang 310016, Hangzhou, China
}

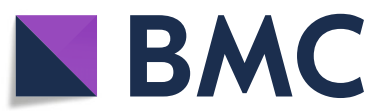

(c) The Author(s). 2020 Open Access This article is licensed under a Creative Commons Attribution 4.0 International License, which permits use, sharing, adaptation, distribution and reproduction in any medium or format, as long as you give appropriate credit to the original author(s) and the source, provide a link to the Creative Commons licence, and indicate if changes were made. The images or other third party material in this article are included in the article's Creative Commons licence, unless indicated otherwise in a credit line to the material. If material is not included in the article's Creative Commons licence and your intended use is not permitted by statutory regulation or exceeds the permitted use, you will need to obtain permission directly from the copyright holder. To view a copy of this licence, visit http://creativecommons.org/licenses/by/4.0/. The Creative Commons Public Domain Dedication waiver (http://creativecommons.org/publicdomain/zero/1.0/) applies to the data made available in this article, unless otherwise stated in a credit line to the data. activation of microglia, and impaired inhibitory modulation [3]. Whereas, the underlying mechanism concerning NP are not fully understood, which causes the absence of effective treatments to alleviate pain substantially.

According to current estimates, approximately $10^{14}$ microbes are residing in the human body and the number of microbial cells is outnumbering the human cells [4]. In humans, the gastrointestinal tract is a huge, populous, and intricate microbial ecological community that mainly contains bacteria, archaea, fungi, protozoa, and viruses. Alteration of gut microbiota or unexpected exposure to specific bacteria in the intestine can regulate the peripheral and central nervous systems (CNS), leading to the change of brain function and illustrating the existence of the microbiota-gut-brain axis. It is now commonly believed that interaction in the microbiotagut-brain axis is bidirectional. Excitingly, the interactive signal transmission has been proved to be involved in different kinds of diseases. Abundant work indicated that gut microbiota indeed plays a predominant role in the 
appearance of visceral pain and provides an infusive research interest in pathological pain linked to gut dysbiosis. The emerging role of gut microbiota in neurological diseases, including chronic pain, has attracted ever more traction recently.

Currently, the relationship between gut microbiota and pain modulation has attracted more and more clinicians' attention along with the advancement of medical science. A growing body of research showed that bacteria could activate nociceptors directly via their products and constitutive elements [5]. During infection, bacterial formyl peptides induce calcium flux and action potentials in nociceptor neurons and thereby result in mechanical pain sensitivity in mice [6, 7]. Moreover, $\alpha-$ hemolysin, one of the pore-forming toxins secreted by Staphylococcus aureus, could induce neuronal firing and spontaneous pain $[7,8]$. Interestingly, previous studies indicated that nociceptor neurons could especially recognize bacterial constitutive/secreted molecules, which are partly involved in the pain signaling $[5,9]$. Besides, viral and fungal pathogens are identified to elicit alteration of pain sensitivity via inducing immune activation [10]. Additionally, there is no denying that microbes may serve as a critical and irreplaceable modulator in the progression of pain transduction according to previous researches.

Emerging evidence strongly demonstrated that gut microbiota plays a crucial role in abdominal pain, opioid tolerance, headache, inflammatory pain, and NP [11]. Among them, the connection establishment between gut microbiota and NP provides significant potential for researchers to overcome this type of refractory pain. Shen et al. investigated the role of gut microbiota in chemotherapy-induced peripheral neuropathy (CIPN) and confirmed that oxaliplatin-induced mechanical hyperalgesia was decreased in both germ-free (GF) mice and mice pretreated with antibiotics [12]. Accordingly, the protection would be abrogated after colonizing the microbiota in GF mice. Lately, a study established a rat model of spared nerve injury (SNI) and demonstrated that the anhedonia susceptible rats prefer to show gut microbiota dysbiosis when compared to sham-operated and resilient rats. Meanwhile, the transplantation of fecal microbiota from SNI rats to the pseudo-GF mice can also alter the severity of NP and the phenotypes of depression-like and anhedonia-like [13]. Although NP is rather difficult to treat and its mechanism remains unclear to date, increasing studies suggest that gut microbiota may be a promising target for improving NP management.

We comprehensively retrieved the PubMed database from 2000 to August 2020 and the retrieved keywords mainly consist of 'neuropathic pain' AND 'gut microbiota', 'neuropathic pain', 'gut microbiota', 'neuropathic pain mechanism', 'neuropathic pain treatment', 'microbiota-gut-brain axis'. All types of literature were narrative review, systemic review, randomized controlled trial, comparative study, and article, respectively. Moreover, additional publications were searched from the bibliographies of relevant articles to guarantee an integrated collection. Collectively, we systematically address recent advances regarding the role of gut microbiota in regulating the incidence and progression of NP and attempt to provide a potential therapeutic strategy for alleviating NP.

\section{Microbiota-gut-brain communication}

The bidirectional communication between the gut and brain involves multiple pathways including immune, neural, endocrine, and metabolic routes. Efferent and afferent fibers form a sophisticated reflexive network between the brain and intestine and facilitate interactions within the microbiota-gut-brain axis [14]. This axis comprises various tissues and organs comprising of glands, immune cells, autonomic nervous systems, brain, intestine, and gut microbiota, which crosstalk with a bidirectional manner to maintain homeostasis (Fig. 1). Over past decades, much work has been carried out to define the role of gut-brain interactions in the setting of gastrointestinal tract functional disorders and other disorders that may be related to dysregulated gut-brain communication [15]. Recently, the microbiota-gut-brain axis has drawn increasing attention with the going deep of the medical research. Additionally, microbiota-gut-brain communication implicated in plenty of pathological conditions including Alzheimer's disease, Parkinson's disease, depression, and pain, which may directly result in the occurrence of disease by disturbing the balance of the axis.

\section{Role of gut microbiota in neuropathic pain Microbiome-associated immune signaling}

Chemokines and cytokines Abundant literature illustrated that the peripheral and central nervous systems impair triggers cascade of reactions, and thereby construct the chemokine-cytokine architecture, which is closely correlated to the occurrence of neuroinflammation $[16,17]$. The alteration of chemokine-cytokine network results in the peripheral sensitization associated with peripheral nociceptive processing [18]. Similarly, glial cells in the spinal dorsal horn (SDH) triggered by inflammatory molecules directly participate in the development of NP via central sensitization [16, 19]. Proinflammatory cytokines and chemokines, such as tumor necrosis factor-alpha (TNF- $\alpha$ ) and interleukin-1 $\beta$ (IL$1 \beta)$, produced by various types of cells including immune cells. These molecules form the main mechanism 


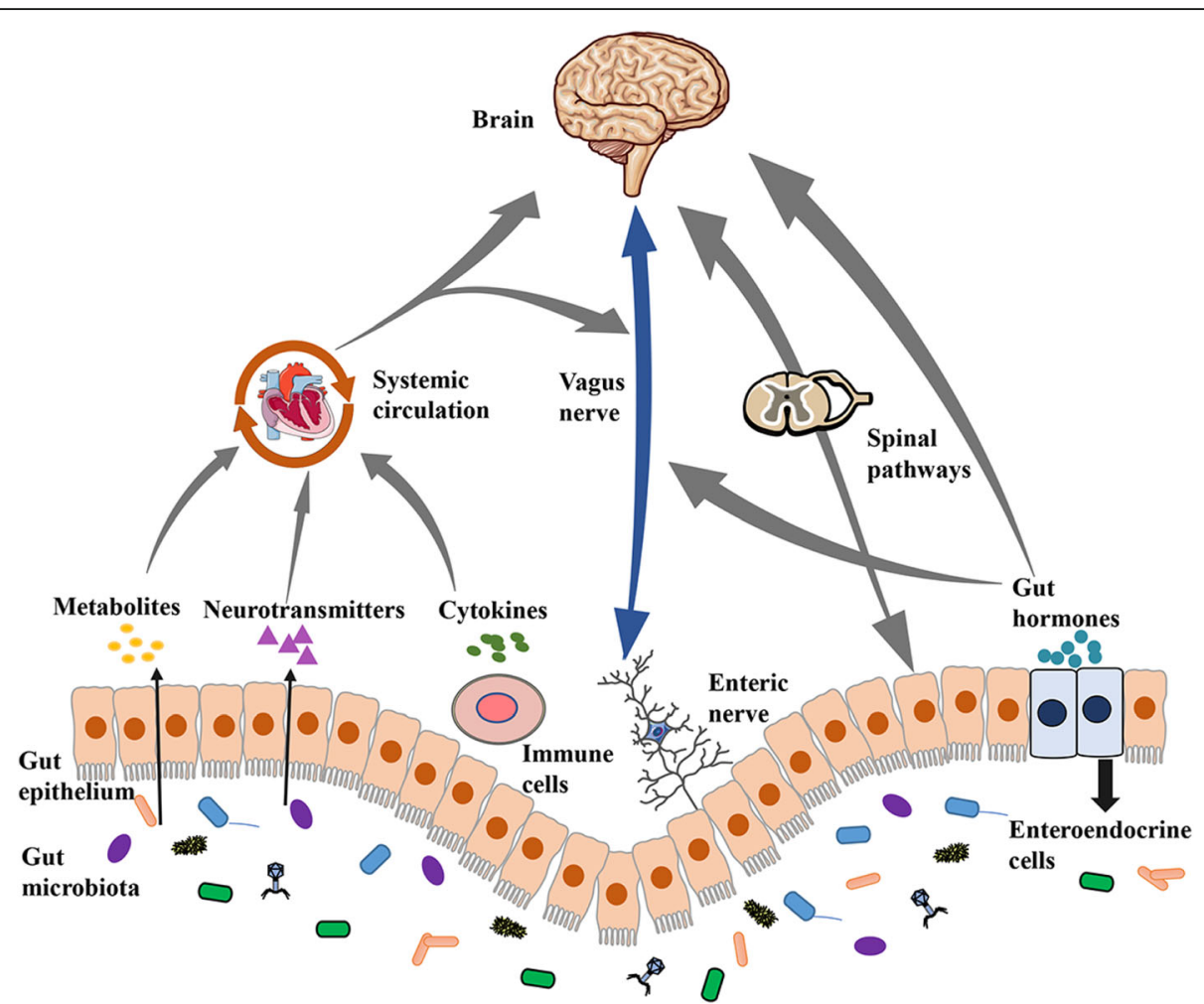

Fig. 1 Communication pathways of the microbiota-gut-brain axis. This graph describes the crosstalk of the microbiota-gut-brain axis, which mainly comprise of four modules: metabolic, neural, immune, and endocrine signaling pathways

that promotes the neuro-immune communication [20] and elicits the spontaneous discharges by directly sensitizing A- and C-fibers, which is associated with allodynia and hyperalgesia following nerve injury [21, 22]. Related studies showed that the inhibition of upregulated chemokines and their receptors in the peripheral and central nervous systems effectively relieves NP [23]. Thus, cytokines and chemokines play a vital role in processes causing NP. Consistently, numerous drugs have been designed to block cytokine and chemokine signaling; nevertheless, preclinical and clinical studies assessing these receptor antagonists are limited.

The alteration of gut microbiota and its metabolites is related to intestinal dysfunction and systemic immune responses that are generally accompanied the release of numerous pro-inflammatory mediators by immune and glial cells. Pathogen-associated molecular patterns (PAMPs) derived from gut microbiota contain a remarkable array of components, including lipopolysaccharides (LPS) and peptidoglycan (PGN), which are released locally, enter the bloodstream and interact with pattern recognition receptors (PRRs) [24, 25]. Also, PAMPs are key mediators of peripheral sensitization of chronic pain [26]. Clinically, chemotherapy-induced destruction of the intestinal epithelial barrier causes intestinal flora to translocate and release harmful endogenous substances.
These substances stimulate PAMPs and PRRs of host antigen-presenting cells and provoke the generation of pro-inflammatory mediators, which constitute an important component of the pathogenesis of CIPN [27]. Shen et al. revealed that the aggregation of macrophages and cytokines in dorsal root ganglion (DRG) are considerably reduced after the administration of oxaliplatin compared with water, demonstrating that the inflammatory response caused by gut microbiota was suppressed in mice treated with antibiotics [12]. Of note, Lactobacillus fermentum KBL374 and KBL375 can prominently increase the production of the antiinflammatory cytokine IL-10, with subsequently inhibiting the expression of other pro-inflammatory cytokines and chemokines [28-30] (Table 1). Also, results from other strains of lactobacillus suggested that these bacteria mediate immunosuppression by decreasing the production of pro-inflammatory cytokines. These results documented that alteration of gut microbiota could lead to the up-regulation and down-regulation of cytokines and chemokines at the same time, which may affect the occurrence of NP. Due to the absence of specific biomarkers for diagnosing NP to date, further studies are needed to research gut microbiota dysbiosis and determine whether gut microbiota influences the development of NP via the induction of immune responses with 
Table 1 Microbial mediators/species associated with the underlying mechanisms of neuropathic pain

\begin{tabular}{|c|c|c|c|}
\hline Microbial mediators or species & Function & $\begin{array}{l}\text { Potential mechanisms related to } \\
\text { neuropathic pain }\end{array}$ & References \\
\hline \multirow[t]{3}{*}{ LPS } & Activate TLR4 & TLR4 contributes to neuropathic pain & Kawai et al. (2010) [31] \\
\hline & $\begin{array}{l}\text { Activate TRPA } 1 \text { in a TLR4-independent } \\
\text { and membrane-delimited manner }\end{array}$ & $\begin{array}{l}\text { The activation of TRPA } 1 \text { can evoke } \\
\text { nociceptive neurons depolarization } \\
\text { and firing }\end{array}$ & Meseguer et al. (2014) [32] \\
\hline & $\begin{array}{l}\text { Activate TRPV1-mediated capsaicin } \\
\text { responses via TLR4 }\end{array}$ & $\begin{array}{l}\text { Capsaicin responses lead to the excitation } \\
\text { of nociception neurons }\end{array}$ & Diogenes et al. (2011) [33] \\
\hline \multirow[t]{2}{*}{ Bacterial flagellin } & Activate TLR5 & $\begin{array}{l}\text { TLR5 facilitates the release of } \\
\text { pro-inflammatory mediators }\end{array}$ & Kawai et al. (2010) [31] \\
\hline & Activate TLR5 & $\begin{array}{l}\text { TLR5-mediated A-fiber blockade } \\
\text { inhibits mechanical allodynia }\end{array}$ & Kawai et al. (2010) [31] \\
\hline Indole, LPS & Regulate the secretion of GLP-1 & $\begin{array}{l}\text { GLP-1 is associated with pain } \\
\text { hypersensitivity }\end{array}$ & $\begin{array}{l}\text { Chimerel et al. (2014) [34], } \\
\text { Nguyen et al. (2014) [35] }\end{array}$ \\
\hline \multirow[t]{2}{*}{ SCFAs } & Activate microglia & $\begin{array}{l}\text { The activation of microglia leads to } \\
\text { pain hypersensitivity }\end{array}$ & Borre et al. (2014) [36] \\
\hline & $\begin{array}{l}\text { Stimulates the production of PYY } \\
\text { and GLP-1 in a FFAR2 and FFAR3 } \\
\text { receptors dependent way }\end{array}$ & $\begin{array}{l}\text { GLP-1, PYY are associated with pain } \\
\text { hypersensitivity }\end{array}$ & $\begin{array}{l}\text { Tolhurst et al. (2012) [37], } \\
\text { Psichas et al. (2015) [38], } \\
\text { Lin et al. (2012) [39] }\end{array}$ \\
\hline PUFAs & An endogenous agonist of TRPV4 & $\begin{array}{l}\text { The activation of TRPV } 4 \text { leads to } \\
\text { peripheral hypersensitivity }\end{array}$ & Cenac et al.(2015) [40] \\
\hline $\begin{array}{l}\text { Bacteria-derived secondary bile } \\
\text { acids }\end{array}$ & $\begin{array}{l}\text { Facilitates the release of GLP-1 and } \\
\text { PYY via TRG5 }\end{array}$ & $\begin{array}{l}\text { GLP-1, PYY are associated with pain } \\
\text { hypersensitivity }\end{array}$ & $\begin{array}{l}\text { Ullmer et al. (2013) [41], } \\
\text { Thomas et al. (2009) [42], } \\
\text { Katsuma et al. (2005) [43] }\end{array}$ \\
\hline $\begin{array}{l}\text { Lactobacillus fermentum KBL374 } \\
\text { and KBL375 }\end{array}$ & $\begin{array}{l}\text { Increase IL-10 secretion while } \\
\text { decrease pro-inflammatory } \\
\text { mediators secretion }\end{array}$ & $\begin{array}{l}\text { IL-10 is associated with anti-inflammatory } \\
\text { effects }\end{array}$ & Jang et al. (2019) [28] \\
\hline Bacteroides fragilis & $\begin{array}{l}\text { Facilitate the polarization of } \\
\text { macrophages to } \mathrm{M} 1 \text { type and } \\
\text { enhance their phagocytosis }\end{array}$ & $\begin{array}{l}\text { M1 macrophages can release } \\
\text { pro-inflammatory cytokines and } \\
\text { express TLRs }\end{array}$ & Deng et al. (2016) [44] \\
\hline Escherichia coli, Lactobacillus & Synthesize GABA & $\begin{array}{l}\text { GABA can reverse allodynia in the } \\
\text { neuropathic pain model }\end{array}$ & $\begin{array}{l}\text { Zhao et al. (2017) [45], } \\
\text { Wu et al. (2017) [46] }\end{array}$ \\
\hline $\begin{array}{l}\text { Escherichia coli, Streptococcus spp., } \\
\text { and Enterococcus spp. }\end{array}$ & Produce 5-HT & 5-HT serve as a special regulator in NP & Guo et al. (2019) [11] \\
\hline Corynebacterium glutamicum & Produce glutamate & $\begin{array}{l}\text { Glutamate can affect hyperalgesia } \\
\text { in neuropathic pain models }\end{array}$ & $\begin{array}{l}\text { Nakayama et al. (2018) [47], } \\
\text { Yang et al. (2017) [48], } \\
\text { Persicke et al. (2015) [49] }\end{array}$ \\
\hline $\begin{array}{l}\text { Lactobacillus, Peptostreptococcus, } \\
\text { Clostridium sporogenes }\end{array}$ & $\begin{array}{l}\text { Generate AHR ligands derived } \\
\text { from tryptophan }\end{array}$ & $\begin{array}{l}\text { Act directly on astrocytes through } \\
\text { AHR and limit inflammation and } \\
\text { neurodegeneration }\end{array}$ & $\begin{array}{l}\text { Zelante et al. (2013) [50], } \\
\text { Wlodarska et al.(2017) [51], } \\
\text { Dodd et al. (2017) [52] }\end{array}$ \\
\hline DSF formulation & Attenuate inflammatory signals & $\begin{array}{l}\text { Neutralize the influence of upregulation } \\
\text { of TRPV1 and TRPV } 4 \text { induced by paclitaxel }\end{array}$ & Castelli et al. (2018) [53] \\
\hline
\end{tabular}

Abbreviations: LPS lipopolysaccharide, TLR Toll-like receptor, TRPA1 transient receptor potential cation channel, subfamily A, member 1, TRPV1 transient receptor potential cation channel, subfamily V, member 1, TRPV4 transient receptor potential cation channel, subfamily V, member 4, SCFAs short-chain fatty acids, PUFAs polyunsaturated fatty acids, GABA $\gamma$-aminobutyric acid, GLP-1 glucagon-like peptide 1, PYY peptide YY, FFAR free fatty acid receptor, TRG5 G protein-coupled bile acid receptor, $A H R$ aryl hydrocarbon receptor, IL-10 interleukin-10

these pro-inflammatory mediators. In addition, studies also could identify microbiota subgroups that play the greatest role to obtain better efficacy.

Toll-like receptors (TLRs) Broadly distributed on most immune cells and other cell types, TLRs are a member of PRRs that activate innate and adaptive immune systems [26]. TLRs are categorized into two types, including extracellular and intracellular receptors. The former recognizes PAMPs, such as LPS derived from microbiota, whereas the latter recognizes the nucleic acids of viruses, bacteria, and hosts $[54,55]$. When activated, their downstream signaling pathways contribute to the sustained production of numerous immune proinflammatory mediators [56]. TLR4 may also play an indispensable role in the occurrence of NP. Previous studies illustrated that hyperalgesia and allodynia in TLR4-mutant mice are significantly reduced in chemotherapy and nerve injury-induced NP models [57, 58]. Different TLRs sense different PAMPs. For example, 
TLR2 detects PGN and lipoteichoic acids, TLR4 binds LPS and TLR5 recognizes bacterial flagellin [31] (Table 1). A series of TLR4-mediated signaling pathways are triggered after TLR4 recognizes LPS and promotes the activation of glial cells. When stimulated by flagellin, TLR5 also facilitates the release of pro-inflammatory mediators from immune cells, which contributes to the development of NP [25]. Interestingly, TLR5 activation simultaneously also results in the blockade of sodium currents mainly in A-fibers of mouse DRG and successfully inhibits mechanical allodynia following chemotherapy, diabetic neuropathy, and nerve injury [59] (Fig. 2).
Thus, we conclude that gut microbiota plays a dual role by acting on the TLR-mediated pain-related conduction pathways. Due to the vague definition of "harmful", it might be excessively simplistic to remove some pathogens from gut microbiota, to improve the pain condition.

Macrophages Numerous macrophages reside in the gastrointestinal tract and play a critical role in regulating body function and maintaining homeostasis. According to different functional phenotypes, macrophages can be polarized into two types: M1 and M2. M1 is

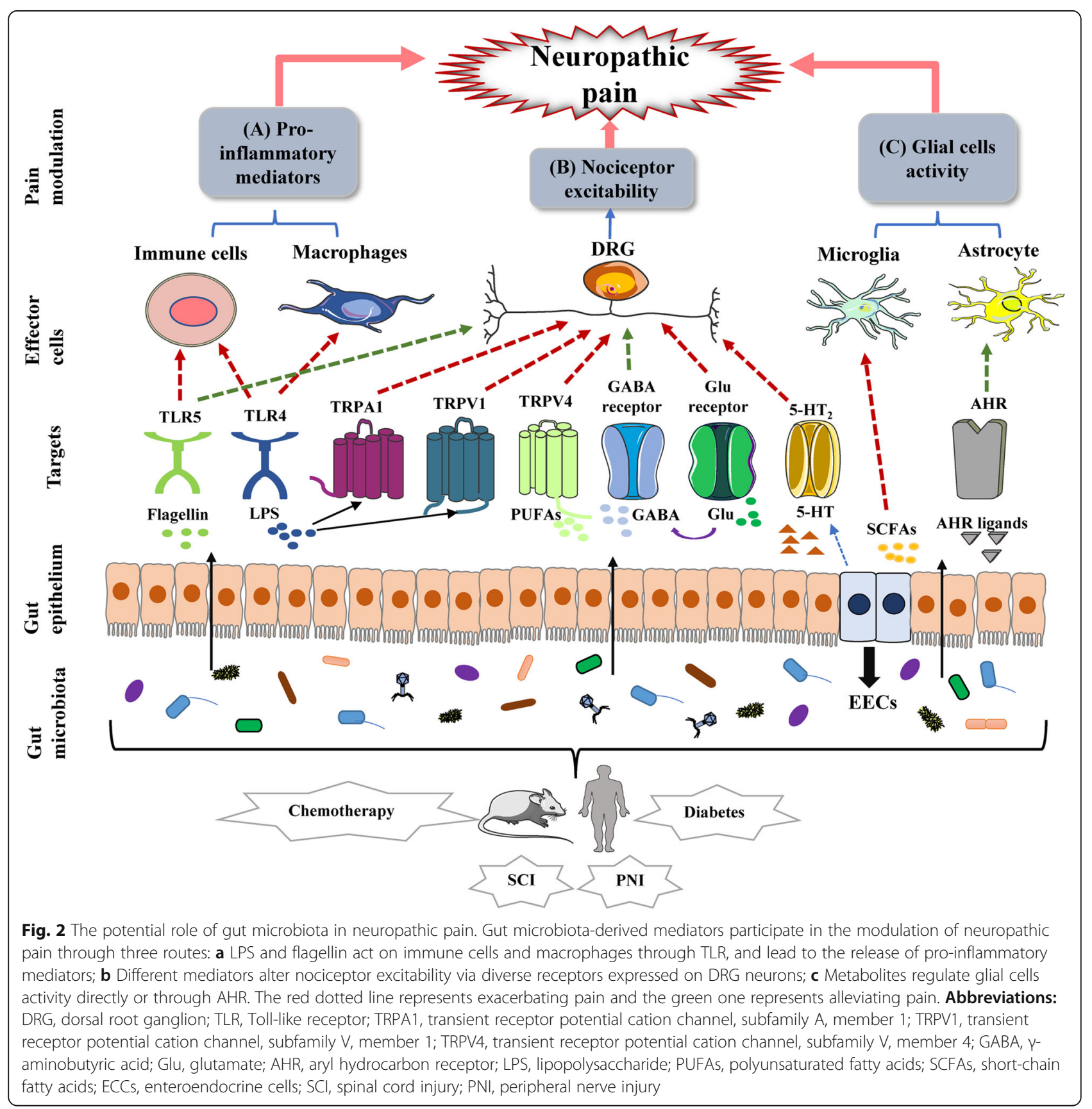


characterized by a high expression of pro-inflammatory cytokines and receptors, while M2 is characterized by a good deal of anti-inflammatory cytokines [60-62]. There is a bilateral communication between macrophages and nociceptors, which is embodied in macrophages releasing pro-inflammatory mediators to 'talk to' nociceptors while macrophages showing 'listening to' neuropeptides and chemokines secreted by nociceptors [63]. Many experimental NP animal models exhibit the activation and accumulation of macrophages. Specific inhibition or consumption of macrophages in these models can effectively prevent pain hypersensitivity [64-67], demonstrating that macrophage is an essential regulator of NP (Fig. 2). It is reported that a new strain of Bacteroides fragilis could facilitate the polarization of macrophages to M1 type and enhance their phagocytosis [44]. Accumulating evidence suggested that when stimulated by gut microbiota dysbiosis, M1 macrophages release proinflammatory cytokines and express TLRs, thus further enhancing neuron-macrophage communication through various pathways. However, a recent study elucidated that gut microbiota could trigger cathepsin $\mathrm{K}$ secretion and then induce TLR4-dependent M2 macrophage polarization [68], which may potentially promote antiinflammatory responses. Grounded on these studies, we conclude that gut microbiota might also play a dual role in macrophage polarization. Given that macrophage polarization and activation is altered in response to the environment [69], how to subtly guide gut microbiota to be more inclined to inhibit the differentiation of M1 macrophages or induce the transformation from M1 to M2 may become a potential treatment to improve NP conditions. Along this direction, the development of an inducing agent with extensive action on microbes represents a significant advance in the goal to specifically block the damage caused by macrophages in NP while maintaining their phagocytic function.

\section{Microbiome-associated neural signaling}

Neurotransmitters Pain perception involves a variety of neurotransmitters, which can be mainly divided into inflammatory mediators and noninflammatory mediators [70]. The most specific of these neurotransmitters are glutamate and GABA, which are the most widely distributed excitatory and inhibitory neurotransmitters in the body, respectively. Both host and bacteria can convert glutamate to GABA [71]. Some previous studies reported that agents promote the release of GABA by activating GABA receptors, thus effectively relieving trigeminal and diabetic-related NP [72, 73]. Braz et al. demonstrated that GABAergic precursor cell transplantation can reverse allodynia in a mouse NP model and propose transplantation as a therapeutic option in various NP-related models [74, 75]. Furthermore, both the increase of glutamate and the administration of glutamate release inhibitors are sufficient to affect hyperalgesia in animal models [76, 77]. Recently, it has been confirmed that some environmental bacteria strains employed in food fermentation can produce glutamate [47-49]. Also, several strains of bacteria, such as Escherichia coli [45], and Lactobacillus [46], synthesize GABA (Table 1, Fig. 2). Excitingly, the probiotic Escherichia coli strain Nissle $1917(\mathrm{EcN})$ can generate a GABA-related analgesic lipopeptide that inhibits downstream responses caused by nociceptor activation after crossing the intestinal epithelial barrier [78]. In summary, glutamate and GABA in the gut are linked to abundant signaling pathways that modulate pain conditions, regulate the release of pro-inflammatory cytokines, and sense or inhibit afferent innervation of the gastrointestinal tract [79]. However, the host itself also produces GABA. Thus, which of these two sources of GABA predominantly stimulates intestinal neurons and the vagus nerve and ultimately plays a greater role in NP remains unknown.

Serotonin (5-HT), as an important neurotransmitter, could effectively modulate the nociceptive response and serve as a special regulator in NP. When $5-\mathrm{HT}$ acts on its receptors, $5-\mathrm{HT}_{1}$ receptor activation create a hyperpolarizing effect; while 5-HT2 and 5-HT3 activation leads to primary nociceptive neurons depolarized in DRG [80] (Fig. 2). Ji et al. found the activation of the $5-\mathrm{HT}_{2 \mathrm{c}}$ receptor in the basolateral amygdala facilitates activities in NPassociated central nucleus [81]. Correspondingly, $5-\mathrm{HT}_{2 \mathrm{c}}$ receptor knockdown contributes to the reduction of NPrelated behaviors [82]. More than $90 \%$ of $5-\mathrm{HT}$ in the body is synthesized by enteroendocrine cells (EECs) and a growing body of literature reveals that the microbiota is correlated with the host level of 5-HT. Notably, 5-HT can be generated by several strains of bacteria, including Escherichia coli, Streptococcus spp., and Enterococcus spp. [11] (Table 1), but whether gut microbiota can produce 5HT by de novo remains unknown. Interestingly, $5-\mathrm{HT}$ is reported to be a structural analog of auxins of Escherichia coli, Rhodospirillum rubrum, and Enterococcus faecalis, and activates the growth of these bacteria. Therefore, it might be a hot spot to investigate whether the microbes are able to influence the host 5-HT biosynthesis, and thereby reverse the colonization and development of special microbiota in the intestine [83]. In a word, these findings suggest that the alteration of the microbes may make a difference in the nociception, which is potentially involved in the progression of NP. Though the mechanisms of these neuroactive molecules referred to NP induction and the production of neurotransmitters affected by gut microbiota being far from explicit, it is no denying that gut microbiota is concerned with NP pathogenesis through neurotransmitter routes. 
Transient receptor potential (TRP) channels TRP channels are ion channel family members and they are widely expressed on primary afferent nociceptors in DRG. TRP channels act as sensors that convert mechanical, chemical, and thermal stimuli into an inward current [84-86]. TRPA1 and TRPM8 are considered as cold transducers that dominantly mediate cold allodynia [87-89], and experimental results indicated that the administration of their specific inhibitors could alleviate cold hypersensitivity induced by physical nerve injury or chemotherapy [87, 90, 91]. Through altering cell-specific expression patterns, TRPV1 upregulates its expression in DRG [92] and then elicits thermal and chemical hyperalgesia [93]. However, there is a large gap in the understanding of endogenous pro-nociceptive agonists that could activate these channels in pain-related diseases. As a toxic byproduct of bacterial lysis, LPS evokes nociceptive neuron depolarization and firing $[7,33,94]$ via the activation of TRPA1 in a TLR4-independent and membrane-delimited manner, supporting the role of TRPA1 in NP [32]. On the other hand, LPS also activates TRPV1-mediated capsaicin responses via TLR4, including intracellular calcium accumulation and inward currents [33], and induces the activation of nociception neurons. Also, polyunsaturated fatty acids (PUFAs) are intestinal microbial metabolites and endogenous agonists of TRPV4 that leads to peripheral hypersensitivity after TRPV4 activation [40, 95] (Fig. 2). On the contrary, the DSF formulation, a high concentration probiotic formulation, attenuates inflammatory signals, thereby neutralizing the upregulation of TRPV1 and TRPV4 induced by paclitaxel. Thus, the DSF formulation is a valid adjuvant agent for inhibiting CIPN [53] (Table 1). Currently, the effect of gut microbiota on ion channels is more concentrated on intermediate media. For example, microbial metabolites act as endogenous agonists of ion channels. Whereas, whether a direct interaction occurs between ion channels and microbes remains unclear.

Microglia Microglial cells are macrophage-like and quiescent immune cells in the CNS, which modulate homeostasis in the spinal cord and brain. Although the precise mechanism of microglia activation in the development of NP has not been fully illustrated, compelling evidence indicates that microglia plays a significant cellular role in the process. In spinal cord injury (SCI) and CIPN models, continuous and massive activation of microglia is widely observed, while a decrease in microgliosis is noted after intrathecal injection with minocycline, contributing to alleviate mechanical allodynia [96-98]. The morphology of microglia within the spinal cord undergoes dramatic changes following increased expression of microglial markers, such as CD11b and Iba1, representing microglial activation after peripheral nerve injury (PNI) [99]. It is well documented that the primary sensory neurons would release microglial activators and associated-signaling molecules are upregulated after PNI, both of which are competent to elicit microgliosis and microglial activation [100]. Additionally, TNF- $\alpha$ and IL-1 $\beta$, two major proinflammatory cytokines, are released and produced by microglia, causing pain conditions through various regulatory mechanisms [101]. Recent emerging evidence has confirmed that microglial activation both in SDH and many brain regions leads to changes in synaptic structure and function and pain hypersensitivity following PNI. Nevertheless, the mechanism by which microglia in these brain regions are activated remains unknown given the long distance from the injured peripheral nerves to the brain [102].

Emerging evidence indicated that the temporal absence of gut microbiota could severely alter the characteristics of microglia. A complex gut microbiota conduces to maintain microglia homeostasis; otherwise, the lack of complex microbiota results in defective microglia. No microglial alteration occurs when microbe-associated molecular patterns are not recognized by various TLRs, demonstrating that microglia may be affected in a microbial-dependent manner [103]. Bacterial products or metabolites such as short-chain fatty acids (SCFAs) serve as a crucial molecule in the maturation and activation of microglia (Fig. 2). These molecules can be translocated from the gut mucosa to the circulatory system and cross the blood-brain barrier (Table 1). Of note, the losing of input signals derived from microbiota in mature microglia can lead to the reacquisition of an immature status. However, the phenotype of microglia can be reversed with the recolonization of complex microbiota in the intestine, which profoundly reveals the significant plasticity of gut microbiota-microglia connection [103]. However, just as the mechanism by which distant microglia cells are activated in the brain remains unclear, the mechanism by which the microbe remotely affects microglia cells in CNS should be explored. We identified that gut microbiota plays an essential role in microglia-mediated signaling pathways in NP.

Astrocyte In the CNS, astrocytes are the dominating population of glia, accounting for approximately $20-40 \%$ [104]; these cells supply metabolic support to neurons and maintain glutamate and electrolyte homeostasis [105-107]. Mounting evidence suggests the key modulator of astrocytes in the pathogenesis of pain, especially NP after nerve injuries. First, it has been reported that pain hypersensitivity following PNI in rodents is linked to astrocyte hypertrophy in SDH. In mouse models, it shows that the NP would be ameliorated by suppressing the proliferation of astrocytes [108, 109]. Second, 
abundant studies elucidate that astrocyte-derived mediators could produce pain hypersensitivity [109]. For instance, the overexpression of $\mathrm{C}-\mathrm{C}$ motif chemokine 2 in astrocytes results in increased hyperalgesia in mice [110]. Third, recent research found that stimulating astrocytes by transient optogenetic leads to mechanical allodynia as soon as 1 hour after the stimulus in naive rats, demonstrating that astrocyte activation completely drives the occurrence of pain [111]. Collectively, according to the breadth of published literature, we reason out that astrocytes a key driver of NP.

Astrocyte activation is influenced by many factors from inside and outside the CNS [112]. Recently, an emerging study reports a new signaling pathway wherein gut microbiota and environmental cues are integrated to modulate astrocyte activity via circHIPK2 [113], which inhibits astrocyte activation [114]. In addition, dietary tryptophan metabolized by gut microbiota can act directly on astrocytes through aryl hydrocarbon receptors (AHR), limiting inflammation and neurodegeneration in the CNS and providing neuroprotective effects [115, 116] (Fig. 2). Meanwhile, microbial metabolite signaling also regulates the production of transforming growth factor- $\alpha$ (TGF $\alpha)$ and vascular endothelial growth factorB (VEGF-B) via microglial AHR, further impacting proinflammatory activities of astrocytes [116]. Notably, derived from tryptophan, AHR ligands are generated by certain types of bacteria, including Lactobacillus [50], Peptostreptococcus [51], and Clostridium sporogenes [52] (Table 1). On the other hand, TGF $\alpha$ produced by microglia facilitates axon regeneration and increases neuronal survival by inducing astrogliosis and neuroprotective factor generation in SCI models $[117,118]$. Thus, we conclude that microglial TGF $\alpha$ promotes salutary astrocyte activities. Currently, the use of commensal bacteria to control TGF $\alpha$-ErbB1 signaling via AHR has been proposed as an alternative strategy for treating SCI [119]. Therefore, targeting of AHR is likely to establish a microbiota-microglia-astrocyte-oriented treatment for NP.

Enteric glia In the enteric nervous system, enteric glial cells are a unique community of peripheral glial cells related to neurons. Enteric glia takes part in neurotransmission by producing and modulating neurotransmitters, and many of these delivery systems are correlated with the excitability of nociceptors [120]. New data demonstrated that some microbial roles are closely associated with the function and development of enteric glia [121], and the formation of the mucosal enteric glial cell network is synchronized with gut microbiota maturation [122, 123]. Moreover, the introduction of a group of normal gut microbiota can restore the population of impaired mucosal glia [123]. Additionally, enteric glia and astrocytes exhibit morphological and functional similarities, potentially indicating a similar role in pain signaling. Anatomically speaking, enteric glial cells are much closer to intestinal flora than glia in the CNS. Given a lack of understanding of how pain signaling communication occurs between gut microbiota and glia in the CNS due to the significant distance, we hypothesize that enteric glial cells are both a structural and functional mediator of this process. Consequently, adjusting gut microbiota to trigger alterations in these will likely contribute to the identification of a novel treatment for NP.

\section{Microbiome-associated endocrine and metabolic signaling}

As the gastrointestinal tract is the largest endocrine organ in the human body, gut hormones produced by the enteroendocrine system have a wide range of targets both within and outside the intestinal lumen. To date, several types of EECs have been identified, and all of them are sensory cells [124]. Multiple pleiotropic gut hormones released from EECs are involved in pain modulation, including glucagon-like peptide 1(GLP-1), neuropeptide $\mathrm{Y}(\mathrm{NPY})$, and peptide $\mathrm{YY}(\mathrm{PYY})$. Previous studies reported that the administration of a GLP-1 ana$\log$, such as exendin-4 [125] and the orthosteric agonist of GLP-1 morroniside [126] could alleviate pain hypersensitivity. NPY, acknowledged as a promising target for the treatment for NP for a long time, is widely expressed in the central and peripheral nerve systems, such as enteric neurons and primary afferent neurons [127]. Another member of the neuropeptide family, PYY is exclusively expressed by EECs [127] and has been demonstrated its involvement in the regulation of somatic and visceral pain sensitivity [128]. At present, there is still a large gap in the research on the relationship between EECs with their secreted gut hormones and NP conduction. Given that EECs have a long lifespan [129], they are potentially integrated into the pain-related signaling network involving the immune and nervous systems. Thus, these gut hormones are likely not only endocrine mediators but also immune and neural mediators.

Given the direct dialogue between EECs and gut microbiota at the enteroendocrine interface, their interaction influences gut hormone metabolism. Strikingly, bacterial metabolites directly activate the overwhelming majority of $\mathrm{L}$ cells in the distal intestine. For example, the $\mathrm{G}$ protein-coupled bile acid receptor (TGR5) distributed on L cells is activated by bacteria-derived secondary bile acids, thus facilitating the release of GLP-1 and PYY from peripheral [41-43]. Additionally, bacterial LPS and the indole produced by bacteria regulate the secretion of GLP-1 [34, 35]. Furthermore, SCFA signaling promotes the generation of PYY and GLP-1 in a free fatty acid receptor 2 ( FFAR2 ) and FFAR3 receptor-dependent 
manner [37-39] (Table 1). On the other hand, gut microbiota also impacts bile acid metabolism in the host [130]. When bile acids bind to TGR5 expressed in macrophages and primary sensory neurons, two dramatically different outcomes are noted. The activation of neurons in DRG leads to hyperexcitability in a TRPA1-dependent manner, while activation of peripheral macrophages contributes to analgesia [131, 132]. Taken together, through its metabolites and its influence on host metabolism, gut microbiota has established a microbiota-endocrinemetabolic system. Although a considerable portion of gut hormones secreted by EECs are related to pain, more direct preclinical, and clinical studies indicating that hormone molecules participate in signaling involved in the pathogenesis of NP are lacking. To a large extent, gut microbial metabolites potentially participate in NP development through immune and neural signaling pathways, but the existence of an endocrinemetabolism-mediated mechanism also requires further research.

Overall, gut microbiota serves as the intersection of immune, neural, endocrine, and metabolic signaling pathways and has become an intense focus of research. Based on the exciting results in neuroscience over recent years, gut microbiota undoubtedly facilitates the formation of complex and enormous networks and thereby results in the occurrence and development of NP as a pivotal and systematic modulator.

\section{Potential therapeutic strategy}

\section{Probiotics and antibiotics}

Given their tremendous potential to alter gut microbiota, probiotics are living bacteria that can provide health benefits, including improved digestion, enhanced immunity, and reduced risk of some diseases [133, 134]. Probiotics alleviate irritable bowel syndrome (IBS), inflammatory bowel disease, and other intestinal dysfunctions. Previous studies suggested that visceral hypersensitivity is improved after the consumption of probiotics in animal models [135]. For instance, VSL\#3 and Lactobacillus paracasei reverse hyperalgesia and allodynia during colorectal distention [136, 137]. Moreover, probiotics impact the production of cytokines and the expression levels of TLR2 and TLR4, thus modulating immune system activity (Fig. 3). Therefore, probiotics may serve as an inhibitor in immune signaling transmission associated with NP. Despite the view proposed that probiotics affect the nerve function of the gut, there is little work to explicitly and directly prove the veracity of this claim. Shen and colleagues illustrated mechanical hyperalgesia is reduced both in mice preprocessed with antibiotics and GF mice in the CIPN model [12]. Since neither probiotics nor pathogenic bacteria exist in GF mice, the therapeutic effect of antibiotics on CIPN cannot be determined or excluded. In summary, probiotics and antibiotics may change the complexity or activity of microbiota via different mechanisms, but both

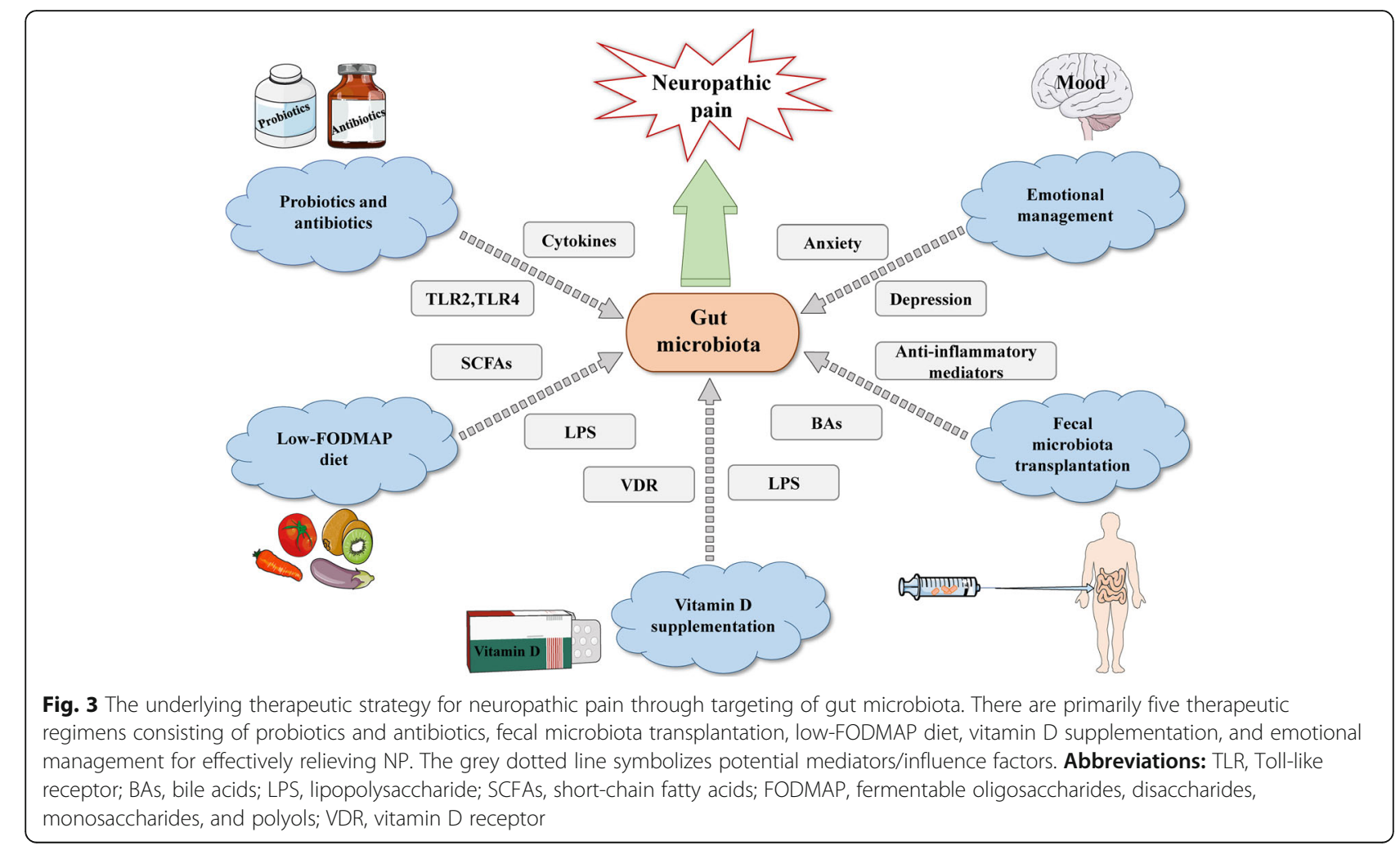


agents potentially relieve pain in animals and humans. Despite promising findings reported for probiotic and antibiotic therapies, their side effects cannot be ignored. However, research remains at an exploratory stage in this field, reminding us of the need to perform more preclinical and clinical work to investigate the role of probiotics and antibiotics treatment in NP based on gut microbiota.

\section{Fecal microbiota transplantation (FMT)}

Recently, the restoration of gut microbiota to the predisease state has become a vital novel treatment, and the new trend of FMT has been used to cure several diseases, such as ulcerative colitis [138] and Clostridium difficile infection [139]. Surprisingly, it is reported that a patient diagnosed with fibromyalgia completely recover after the fecal microbiota transplantation [140], making chronic refractory pain-related diseases a potential therapeutic indication of the treatment. Although fibromyalgia is excluded from the diagnosis of NP since 2011, the pathophysiology of fibromyalgia includes small fiber neuropathy, suggesting a partial overlap between the two pathogeneses. The underlying mechanism of FMT that has been proposed to date suggests that it might play a role in pain via immune and metabolic signal transduction. On one hand, certain components of the transplanted healthy flora may evoke accelerated genesis of anti-inflammatory mediators, thereby counteracting the pro-inflammatory mediators. On the other side, FMT acts as a seemingly prominent player in bile acid metabolism, promptly helping to restore secondary bile acid metabolism in patients [141, 142] (Fig. 3). Although the exact treatment mechanism of FMT has not been revealed, its significant potential in the treatment of chronic pain, including NP, cannot be ignored.

\section{Low-FODMAP diet}

Furthermore, a dietary cure named low-FODMAP (fermentable oligosaccharides, disaccharides, monosaccharides, and polyols) modifies the complex and diverse nature of gut microbiota and its metabolic output. A high-FODMAPs diet results in increasing levels of LPS derived from the microbial community and the imbalance of gut microbiota, whereas a low-FODMAP diet has a lower level of LPS [143]. Therefore, the lowFODMAP diet tends to contribute to protect the intestinal barrier and reduce gut mucosal inflammation by regulating the level of LPS. In addition, some research suggested that the low-FODMAP diet may also lead to the decreased production of SCFAs in the gut [144]. An animal study demonstrated that SCFAs are correlated with abdominal hypersensitivity [145]. Given that a higher concentration of SCFAs is linked to the symptomatology of IBS, reducing SCFAs may be another approach by which this dietary intervention plays its role. Notably, findings are incompatible regarding the impact of the low-FODMAP diet on SCFAs. It found that the concentration of SCFAs makes no difference between the dietary intervention and controls in two randomized controlled trials of IBS [146, 147]. A small part of patients with IBS suffers from refractory and constant pain, manifesting more as a neuropathic process to a large extent, thus making the visceral pain of IBS adherence to the characters of NP at least. Although there is a lack of direct research on NP and the low-FODMAP diet so far, a large number of studies have confirmed the effectiveness of this dietary intervention on curing IBS through potential gut microbiota-related pathways. Logically, the dietary intervention co-implemented with microbe-targeted therapy is likely to be an emerging approach for NP treatment (Fig. 3).

\section{Vitamin D supplementation}

Vitamin D, a neurotrophic hormone and neuroactive steroid, triggers a series of signal conduction systems including pain. In recent years, more and more studies have confirmed that hypovitaminosis D is an independent risk predictor of diabetic neuropathy progression [148]. Some research also proposed that vitamin $\mathrm{D}$ deficiency plays a novel role in the involvement of the mechanistic pathway of multiple sclerosis $[149,150]$. It has been known for decades that the lack of vitamin D results in the decreased absorption of calcium, and induces gut stasis. Unfortunately, the abnormality of intestinal motility enhanced gut permeability allowing a growing release and transfer of endotoxins from gut microbiota [150]. In the long term, translocated LPS stimulates the increased production of pro-inflammatory mediators, ultimately causing neuroinflammation and contributing to the development of multiple sclerosis. In addition to impacting on the gut barrier, vitamin $\mathrm{D}$ may change the composition of gut microbiota communities via activating vitamin $\mathrm{D}$ receptor signaling [151]. Expressed in muscle tissue and CNS, these receptors are associated with innate immune response [152], which has an advantageous effect on keeping homeostasis from disturbance related to neuropathy to some extent [153]. Several previous works illustrated that a high dose of vitamin D supplementation significantly conduces to decrease typical pathogen species and increase the abundance of phylotype of microbes in the gut [154]. Though numerous studies have reported that vitamin D supplementation prevents neuronal degeneration and improves cold allodynia, mechanical, and heat hyperalgesia in the rat models of NP $[155,156]$, the proven mechanism remains uncertain. Based on these findings, future studies could address more insights on vitamin D and gut microbiota and exploit a novel and promising strategy to treat or prevent NP (Fig. 3). 


\section{Emotional management}

Presently, numerous studies indicated that depression and anxiety play an instrumental role in the occurrence and development of NP. Clinical research showed that certain antidepressants indeed attenuate the symptom of NP. Whereas, there is a lack of animal models to effectively account for the impact of emotional outcomes on NP. Most strikingly, some literature documented that gut microbiota is closely correlated with psychiatry including depression and anxiety [157]. Preclinical studies suggested that depression induced by early life stress/surgical procedures leads to the alteration of gut microbiota [158, 159]. Correspondingly, the modulation of gut microbiota also affects behaviors related to depression. Furthermore, compelling evidence documented that anxiety-like behaviors could be influenced by the altered gut microbiota [160, 161], and gut microbiota also transfers the anxious phenotype in turn [162, 163]. Thus, the microbiota may be an underlying therapeutic target for psychiatry. Achieving favorable emotional management via the manipulation of gut microbiota is conducive to relief NP by controlling pain comorbidities (Fig. 3).

\section{Discussion and conclusions}

As more and more precise instruments have been designed to identify NP, assessment of its prevalence and socioeconomic influence have risen. The incapacity of targeting underlying mechanisms accurately results in a lower cure success rate. Following the concept of the microbiota-gut-brain axis proposed, accumulating attention is concentrated on the role of gut microbiota in NP, which is conceptually appealing and provides an emerging perspective. This review comprehensively summarizes the current research status of gut microbiota involved in regulating the pathogenesis of NP through various signaling pathways and deeply discusses the feasibility and challenges of targeting of gut microbiota for treating NP. As the saying goes "all disease begins in the gut", the microbiota-gut-brain axis provides a more scientific explanation for illustrating the basic theory. Along with this axis, we integrate the existing elements associated with the mechanism of NP and establish a complicated immune-neural-endocrine-metabolic systemic network.

Currently, inadequate studies could fully clarify the sophisticated principle concerning the relationship between gut microbiota and NP. A diverse array of intermediate constructs a bridge between both, but some phenomena lack rational explanations mechanistically. One question is how the dysfunctional gut microbiota and its derived mediators transfer into DRG and some even cross the blood-brain barrier
(BBB) into the CNS. Although some previous studies documented several pieces of evidence to support the capability of gut microbiota to impact on BBB permeability $[164,165]$, the proven mechanism is still unclear. Logically, we have to admit that gut microbiota is correlative with NP instead of causal and mentioned signaling pathways of NP reinforce each other and act concurrently. In terms of mechanisms, it will be a great success if aiming at part of a matter along the signal transduction pathways contributes to improving NP-related symptoms.

Present therapies of NP are usually curative, and surplus pain is common even during treatment. Several safer, more economical, and less invasive settlements are more adapted to some patients, and thus the therapeutic approach step by step is cautious [166]. In lots of different situations, the complexities and difficulties of individual cases may reveal the need for multimodal and multidisciplinary NP management strategies. Regarding drug therapy, clinicians are required to pore over the efficacy, the adverse effects, as well as any comorbidities [167]. Additionally, the interventional management of NP is fraught with lots of practical challenges and ethical bias [168]. Therefore, the proposed approach such as low-FODMAP diet, vitamin D supplementation, and emotional management are much less risky, operationally easier, and more acceptable psychologically. Excluded traditional drugs and surgery, these emerging treatments are likely to enjoy high popularity. But then again, we must acknowledge that some controversial applications and secondary action exist. Certain previous research claimed that antibiotics improve the condition of NP, while some illustrated antibiotics could result in hyperalgesia [27]. The administration of antibiotics in different dosage and choice, and differences in components of antibiotics lead to distinct dysfunction of gut microbiota deserve to be discussed. As for FMT, though some anaerobic microbes confirmed to be successfully cultured [169] until recently multitude of gut microbiota cannot be cultivated [170]. Furthermore, the side effects of FMT comprise some self-limiting abdominal uncomfortableness, and, rarely, contagious diseases that are difficult to detect by testing [171], which also needs to be alert.

So far concerned, majority studies have focused on the general role of gut microbiota in NP, but the more detailed characterization of the microbiome population, species, and activity in the pain progression and whether gut microbiota can be a biomarker for NP remains unknown. As long as the most beneficial microbial components for a particular clinical status is determined, the difficulty would be to change the microbiota characteristics to replicate this composition as much as possible. The further step will be manipulating gut microbiota 
more precisely, for instance by bringing in specific microbes to defeat cacoethic strains. Collectively, there being tremendous enthusiasm for the microbiome in academia, targeting gut microbiota has become a rapidly growing therapeutic approach for a wide range of diseases including NP, contributing to facilitating the translation of this finding from bench to bedside.

\section{Abbreviations}

NP: Neuropathic pain; CIPN: Chemotherapy-induced peripheral neuropathy; DRG: Dorsal root ganglion; TLR: Toll-like receptor; TRP: Transient receptor potential; AHR: Aryl hydrocarbon receptor; TGR5: G protein-coupled bile acid receptor; FFAR: Free fatty acid receptor; PGN: Peptidoglycan;

PAMPS: Pathogen-associated molecular patterns; PRRs: Pattern recognition receptors; LPS: Lipopolysaccharide; PUFAs: Polyunsaturated fatty acids; SCFAs: Short-chain fatty acids; ECCs: Enteroendocrine cells; CNS: Central nerve system; TGF-a: Transforming growth factor-a; VEGF-B: Vascular endothelial growth factor-B; GLP-1: Glucagon-like peptide 1; NPY: Neuropeptide Y; PYY: Peptide YY; GF: Germ-free; SCl: Spinal cord injury; PNI: Peripheral nerve injury; BAs: Bile acids; FODMAP: Fermentable oligosaccharides, disaccharides, monosaccharides, and polyols; FMT: Fecal microbiota transplantation; IBS: Irritable bowel syndrome; BBB: Blood-brain barrier

\section{Acknowledgements}

Not applicable.

\section{Authors' contributions}

$B B L, Y T W, P Z$ and GC jointly participated in designing this study. BBL, YTW, YYY and $Y Z$ collected and analyzed these literatures. BBL and YTW drafted this original manuscript. BBL and PZ made these figures. BBL, PZ and GC revised this manuscript.

\section{Funding}

This study was supported by the National Natural Science Foundation of China (No.81371214 and No.81671063), the Key Program of the Natural Science Foundation of Zhejiang, China (No. LZ19H090003), and the medical and health science and technology project of Zhejiang (Grant No. 2019RC044)

\section{Availability of data and materials}

All data were included.

\section{Ethics approval and consent to participate}

Not applicable.

\section{Consent for publication}

Not applicable.

\section{Competing interests}

The authors declare that they have no competing interests.

Received: 15 June 2020 Accepted: 10 August 2020

Published online: 17 August 2020

\section{References}

1. van Hecke O, Austin SK, Khan RA, Smith BH, Torrance N (2014) Neuropathic pain in the general population: a systematic review of epidemiological studies. Pain 155(4):654-662

2. Freynhagen $R$, Baron $R$, Tölle T, Stemmler E, Gockel U, Stevens M, Maier C (2006) Screening of neuropathic pain components in patients with chronic back pain associated with nerve root compression: a prospective observational pilot study (MIPORT). Curr Med Res Opin 22(3):529-537

3. von Hehn CA, Baron R, Woolf CJ (2012) Deconstructing the neuropathic pain phenotype to reveal neural mechanisms. Neuron 73(4):638-652

4. Sender R, Fuchs S, Milo R (2016) Revised estimates for the number of human and bacteria cells in the body. PLoS Biol 14(8):e1002533

5. Defaye M, Gervason S, Altier C, Berthon J-Y, Ardid D, Filaire E, Carvalho FA (2020) Microbiota: a novel regulator of pain. J Neural Transm 127(4):445-465
6. Southgate EL, He RL, Gao J-L, Murphy PM, Nanamori M, Ye RD (2008) Identification of formyl peptides from Listeria monocytogenes and Staphylococcus aureus as potent chemoattractants for mouse neutrophils. J Immunol 181(2):1429-1437

7. Chiu IM, Heesters BA, Ghasemlou N, Von Hehn CA, Zhao F, Tran J, Wainger B, Strominger A, Muralidharan S, Horswill AR et al (2013) Bacteria activate sensory neurons that modulate pain and inflammation. Nature 501(7465): $52-57$

8. Blake KJ, Baral P, Voisin T, Lubkin A, Pinho-Ribeiro FA, Adams KL, Roberson DP, Ma YC, Otto M, Woolf CJ et al (2018) Staphylococcus aureus produces pain through pore-forming toxins and neuronal TRPV1 that is silenced by QX-314. Nat Commun 9(1):37

9. Yang NJ, Chiu IM (2017) Bacterial signaling to the nervous system through toxins and metabolites. J Mol Biol 429(5):587-605

10. Chiu IM (2018) Infection, pain, and itch. Neurosci Bull 34(1):109-119

11. Guo R, Chen L-H, Xing C, Liu T (2019) Pain regulation by gut microbiota: molecular mechanisms and therapeutic potential. Br J Anaesth 123(5):637654

12. Shen S, Lim G, You Z, Ding W, Huang P, Ran C, Doheny J, Caravan P, Tate S, Hu K et al (2017) Gut microbiota is critical for the induction of chemotherapy-induced pain. Nat Neurosci 20(9):1213-1216

13. Yang C, Fang X, Zhan G, Huang N, Li S, Bi J, Jiang R, Yang L, Miao L, Zhu B et al (2019) Key role of gut microbiota in anhedonia-like phenotype in rodents with neuropathic pain. Transl Psychiatry 9(1):57

14. Furness JB (2012) The enteric nervous system and neurogastroenterology. Nat Rev Gastroenterol Hepatol 9(5):286-294

15. Rea K, O'Mahony SM, Dinan TG, Cryan JF (2017) The role of the gastrointestinal microbiota in visceral pain. Handb Exp Pharmacol 239:269287

16. Scholz J, Woolf CJ (2007) The neuropathic pain triad: neurons, immune cells and glia. Nat Neurosci 10(11):1361-1368

17. Ren K, Dubner R (2010) Interactions between the immune and nervous systems in pain. Nat Med 16(11):1267-1276

18. Thacker MA, Clark AK, Marchand F, McMahon SB (2007) Pathophysiology of peripheral neuropathic pain: immune cells and molecules. Anesth Analg 105(3):838-847

19. Milligan ED, Watkins LR (2009) Pathological and protective roles of glia in chronic pain. Nat Rev Neurosci 10(1):23-36

20. Marchand F, Perretti M, McMahon SB (2005) Role of the immune system in chronic pain. Nat Rev Neurosci 6(7):521-532

21. Wang XM, Lehky TJ, Brell JM, Dorsey SG (2012) Discovering cytokines as targets for chemotherapy-induced painful peripheral neuropathy. Cytokine 59(1):3-9

22. Schafers M, Sorkin L (2008) Effect of cytokines on neuronal excitability. Neurosci Lett 437(3):188-193

23. Jiang BC, Liu T, Gao YJ (2020) Chemokines in chronic pain: cellular and molecular mechanisms and therapeutic potential. Pharmacol Ther 212: 107581

24. Miller RE, Ishihara S, Tran PB, Golub SB, Last K, Miller RJ, Fosang AJ, Malfait AM (2018) An aggrecan fragment drives osteoarthritis pain through toll-like receptor 2. JCl Insight 3(6):e95704

25. Das N, Dewan V, Grace PM, Gunn RJ, Tamura R, Tzarum N, Watkins LR, Wilson IA, Yin H (2016) HMGB1 activates proinflammatory signaling via TLR5 leading to allodynia. Cell Rep 17(4):1128-1140

26. Liu T, Gao YJ, Ji RR (2012) Emerging role of toll-like receptors in the control of pain and itch. Neurosci Bull 28(2):131-144

27. Zhong S, Zhou Z, Liang Y, Cheng X, Li Y, Teng W, Zhao M, Liu C, Guan M, Zhao C (2019) Targeting strategies for chemotherapy-induced peripheral neuropathy: does gut microbiota play a role? Crit Rev Microbiol 45(4):369-393

28. Jang YJ, Kim WK, Han DH, Lee K, Ko G (2019) Lactobacillus fermentum species ameliorate dextran sulfate sodium-induced colitis by regulating the immune response and altering gut microbiota. Gut Microbes 10(6):696-711

29. de Roock S, van Elk M, van Dijk ME, Timmerman HM, Rijkers GT, Prakken BJ, Hoekstra MO, de Kleer IM (2010) Lactic acid bacteria differ in their ability to induce functional regulatory T cells in humans. Clin Exp Allergy 40(1):103110

30. de Roock S, van Elk M, Hoekstra MO, Prakken BJ, Rijkers GT, de Kleer IM (2011) Gut derived lactic acid bacteria induce strain specific CD4(+) T cell responses in human PBMC. Clin Nutr 30(6):845-851

31. Kawai T, Akira S (2010) The role of pattern-recognition receptors in innate immunity: update on Toll-like receptors. Nat Immunol 11(5):373-384 
32. Meseguer $V$, Alpizar YA, Luis E, Tajada S, Denlinger B, Fajardo O, Manenschijn J-A, Fernández-Peña C, Talavera A, Kichko T et al (2014) TRPA1 channels mediate acute neurogenic inflammation and pain produced by bacterial endotoxins. Nat Commun 5:3125

33. Diogenes A, Ferraz CCR, Akopian AN, Henry MA, Hargreaves KM (2011) LPS sensitizes TRPV1 via activation of TLR4 in trigeminal sensory neurons. J Dent Res 90(6):759-764

34. Chimerel C, Emery E, Summers DK, Keyser U, Gribble FM, Reimann F (2014) Bacterial metabolite indole modulates incretin secretion from intestinal enteroendocrine L cells. Cell Rep 9(4):1202-1208

35. Nguyen AT, Mandard S, Dray C, Deckert V, Valet P, Besnard P, Drucker DJ, Lagrost L, Grober J (2014) Lipopolysaccharides-mediated increase in glucose-stimulated insulin secretion: involvement of the GLP-1 pathway. Diabetes 63(2):471-482

36. Borre YE, O'Keeffe GW, Clarke G, Stanton C, Dinan TG, Cryan JF (2014) Microbiota and neurodevelopmental windows: implications for brain disorders. Trends Mol Med 20(9):509-518

37. Tolhurst G, Heffron H, Lam YS, Parker HE, Habib AM, Diakogiannaki E, Cameron J, Grosse J, Reimann F, Gribble FM (2012) Short-chain fatty acids stimulate glucagon-like peptide-1 secretion via the G-protein-coupled receptor FFAR2. Diabetes 61(2):364-371

38. Psichas A, Sleeth ML, Murphy KG, Brooks L, Bewick GA, Hanyaloglu AC, Ghatei MA, Bloom SR, Frost G (2015) The short chain fatty acid propionate stimulates GLP-1 and PYY secretion via free fatty acid receptor 2 in rodents. Int J Obes 39(3):424-429

39. Lin HV, Frassetto A, Kowalik EJ, Nawrocki AR, Lu MM, Kosinski JR, Hubert JA, Szeto D, Yao X, Forrest G et al (2012) Butyrate and propionate protect against diet-induced obesity and regulate gut hormones via free fatty acid receptor 3-independent mechanisms. PLoS ONE 7(4):e35240

40. Cenac N, Bautzova T, Le Faouder P, Veldhuis NA, Poole DP, Rolland C, Bertrand J, Liedtke W, Dubourdeau M, Bertrand-Michel J et al (2015) Quantification and potential functions of endogenous agonists of transient receptor potential channels in patients with irritable bowel syndrome. Gastroenterology 149(2):433-444

41. Ullmer C, Alvarez Sanchez R, Sprecher U, Raab S, Mattei P, Dehmlow H, Sewing S, Iglesias A, Beauchamp J, Conde-Knape K (2013) Systemic bile acid sensing by $\mathrm{G}$ protein-coupled bile acid receptor 1 (GPBAR1) promotes PYY and GLP-1 release. Br J Pharmacol 169(3):671-684

42. Thomas C, Gioiello A, Noriega L, Strehle A, Oury J, Rizzo G, Macchiarulo A, Yamamoto H, Mataki C, Pruzanski M et al (2009) TGR5-mediated bile acid sensing controls glucose homeostasis. Cell Metab 10(3):167-177

43. Katsuma S, Hirasawa A, Tsujimoto G (2005) Bile acids promote glucagon-like peptide-1 secretion through TGR5 in a murine enteroendocrine cell line STC-1. Biochem Biophys Res Commun 329(1):386-390

44. Deng H, Li Z, Tan Y, Guo Z, Liu Y, Wang Y, Yuan Y, Yang R, Bi Y, Bai Y et al (2016) A novel strain of Bacteroides fragilis enhances phagocytosis and polarises M1 macrophages. Sci Rep 6:29401

45. Zhao A, Hu X, Wang X (2017) Metabolic engineering of Escherichia coli to produce gamma-aminobutyric acid using xylose. Appl Microbiol Biotechnol 101(9):3587-3603

46. Wu Q, Shah NP (2017) High gamma-aminobutyric acid production from lactic acid bacteria: emphasis on Lactobacillus brevis as a functional dairy starter. Crit Rev Food Sci Nutr 57(17):3661-3672

47. Nakayama Y, Hashimoto K-I, Sawada Y, Sokabe M, Kawasaki H, Martinac B (2018) Corynebacterium glutamicum mechanosensitive channels: towards unpuzzling "glutamate efflux" for amino acid production. Biophys Rev 10(5): 1359-1369

48. Yang J, Yang S (2017) Comparative analysis of Corynebacterium glutamicum genomes: a new perspective for the industrial production of amino acids. BMC Genomics 18(Suppl 1):940

49. Persicke M, Albersmeier A, Bednarz H, Niehaus K, Kalinowski J, Rückert C (2015) Genome sequence of the soil bacterium Corynebacterium callunae type strain DSM 20147(T). Stand Genomic Sci 10:5

50. Zelante T, lannitti RG, Cunha C, De Luca A, Giovannini G, Pieraccini G, Zecchi R, D'Angelo C, Massi-Benedetti C, Fallarino F et al (2013) Tryptophan catabolites from microbiota engage aryl hydrocarbon receptor and balance mucosal reactivity via interleukin-22. Immunity 39(2):372-385

51. Wlodarska M, Luo C, Kolde R, d'Hennezel E, Annand JW, Heim CE, Krastel P, Schmitt EK, Omar AS, Creasey EA et al (2017) Indoleacrylic acid produced by commensal peptostreptococcus species suppresses inflammation. Cell Host Microbe 22(1):25-37
52. Dodd D, Spitzer MH, Van Treuren W, Merrill BD, Hryckowian AJ, Higginbottom SK, Le A, Cowan TM, Nolan GP, Fischbach MA et al (2017) A gut bacterial pathway metabolizes aromatic amino acids into nine circulating metabolites. Nature 551(7682):648-652

53. Castelli V, Palumbo P, d'Angelo M, Moorthy NK, Antonosante A, Catanesi M, Lombardi F, lannotta D, Cinque B, Benedetti E et al (2018) Probiotic DSF counteracts chemotherapy induced neuropathic pain. Oncotarget 9(46): 27998-28008

54. Chen JQ, Szodoray P, Zeher M (2016) Toll-like receptor pathways in autoimmune diseases. Clin Rev Allergy Immunol 50(1):1-17

55. Bettoni I, Comelli F, Rossini C, Granucci F, Giagnoni G, Peri F, Costa B (2008) Glial TLR4 receptor as new target to treat neuropathic pain: efficacy of a new receptor antagonist in a model of peripheral nerve injury in mice. Glia 56(12):1312-1319

56. Gao W, Xiong Y, Li Q, Yang H (2017) Inhibition of toll-like receptor signaling as a promising therapy for inflammatory diseases: a journey from molecular to nano therapeutics. Front Physiol 8:508

57. Park HJ, Stokes JA, Corr M, Yaksh TL (2014) Toll-like receptor signaling regulates cisplatin-induced mechanical allodynia in mice. Cancer Chemother Pharmacol 73(1):25-34

58. Stokes JA, Cheung J, Eddinger K, Corr M, Yaksh TL (2013) Toll-like receptor signaling adapter proteins govern spread of neuropathic pain and recovery following nerve injury in male mice. J Neuroinflammation 10:148

59. Xu ZZ, Kim YH, Bang S, Zhang Y, Berta T, Wang F, Oh SB, Ji RR (2015) Inhibition of mechanical allodynia in neuropathic pain by TLR5-mediated Afiber blockade. Nat Med 21(11):1326-1331

60. Biswas SK, Mantovani A (2010) Macrophage plasticity and interaction with lymphocyte subsets: cancer as a paradigm. Nat Immunol 11(10):889-896

61. Wynn TA, Vannella KM (2016) Macrophages in tissue repair, regeneration, and fibrosis. Immunity 44(3):450-462

62. Sica A, Mantovani A (2012) Macrophage plasticity and polarization: in vivo veritas. J Clin Invest 122(3):787-795

63. Chen O, Donnelly CR, Ji RR (2020) Regulation of pain by neuro-immune interactions between macrophages and nociceptor sensory neurons. Curr Opin Neurobiol 62:17-25

64. Kobayashi Y, Kiguchi N, Fukazawa Y, Saika F, Maeda T, Kishioka S (2015) Macrophage-T cell interactions mediate neuropathic pain through the glucocorticoid-induced tumor necrosis factor ligand system. J Biol Chem 290(20):12603-12613

65. Liu C-C, Lu N, Cui Y, Yang T, Zhao Z-Q, Xin W-J, Liu X-G (2010) Prevention of paclitaxel-induced allodynia by minocycline: effect on loss of peripheral nerve fibers and infiltration of macrophages in rats. Mol Pain 6:76

66. Kiguchi N, Kobayashi Y, Kadowaki Y, Fukazawa Y, Saika F, Kishioka S (2014) Vascular endothelial growth factor signaling in injured nerves underlies peripheral sensitization in neuropathic pain. J Neurochem 129(1):169-178

67. Echeverry S, Wu Y, Zhang J (2013) Selectively reducing cytokine/chemokine expressing macrophages in injured nerves impairs the development of neuropathic pain. Exp Neurol 240:205-218

68. Li R, Zhou R, Wang H, Li W, Pan M, Yao X, Zhan W, Yang S, Xu L, Ding Y et al (2019) Gut microbiota-stimulated cathepsin K secretion mediates TLR4dependent M2 macrophage polarization and promotes tumor metastasis in colorectal cancer. Cell Death Differ 26(11):2447-2463

69. Murray PJ, Allen JE, Biswas SK, Fisher EA, Gilroy DW, Goerdt S, Gordon S, Hamilton JA, Ivashkiv LB, Lawrence T et al (2014) Macrophage activation and polarization: nomenclature and experimental guidelines. Immunity 41(1):14-20

70. Yam MF, Loh YC, Tan CS, Khadijah Adam S, Abdul Manan N, Basir R (2018) General pathways of pain sensation and the major neurotransmitters involved in pain regulation. Int J Mol Sci 19(8):2164

71. Strandwitz P, Kim KH, Terekhova D, Liu JK, Sharma A, Levering J, McDonald D, Dietrich D, Ramadhar TR, Lekbua A et al (2019) GABA-modulating bacteria of the human gut microbiota. Nat Microbiol 4(3):396-403

72. Vasovic D, Divovic B, Treven M, Knutson DE, Steudle F, Scholze P, Obradovic A, Fabjan J, Brkovic B, Sieghart W et al (2019) Trigeminal neuropathic pain development and maintenance in rats are suppressed by a positive modulator of alpha6 GABAA receptors. Eur J Pain 23(5):973-984

73. Liu P, Yuan HB, Zhao S, Liu FF, Jiang YQ, Guo YX, Wang XL (2018) Activation of $G A B A B$ receptor suppresses diabetic neuropathic pain through toll-like receptor 4 signaling pathway in the spinal dorsal horn. Mediat Inflamm 2018:6016272 
74. Braz JM, Sharif-Naeini R, Vogt D, Kriegstein A, Alvarez-Buylla A, Rubenstein $J$, Basbaum Al (2012) Forebrain GABAergic neuron precursors integrate into adult spinal cord and reduce injury-induced neuropathic pain. Neuron 74(4): 663-675

75. Braz JM, Wang X, Guan Z, Rubenstein JL, Basbaum Al (2015) Transplantmediated enhancement of spinal cord GABAergic inhibition reverses paclitaxel-induced mechanical and heat hypersensitivity. Pain 156(6):10841091

76. Watson CJ (2016) Insular balance of glutamatergic and GABAergic signaling modulates pain processing. Pain 157(10):2194-2207

77. Osikowicz M, Mika J, Przewlocka B (2013) The glutamatergic system as a target for neuropathic pain relief. Exp Physiol 98(2):372-384

78. Perez-Berezo T, Pujo J, Martin P, Le Faouder P, Galano JM, Guy A, Knauf C, Tabet JC, Tronnet S, Barreau F et al (2017) Identification of an analgesic lipopeptide produced by the probiotic Escherichia coli strain Nissle 1917. Nat Commun 8(1):1314

79. Cryan JF, Dinan TG (2012) Mind-altering microorganisms: the impact of the gut microbiota on brain and behaviour. Nat Rev Neurosci 13(10):701-712

80. Cortes-Altamirano $\mathrm{JL}$, Olmos-Hernandez A, Jaime HB, Carrillo-Mora P, Bandala C, Reyes-Long S, Alfaro-Rodríguez A (2018) Review: 5-HT1, 5-HT2, 5HT3 and 5-HT7 receptors and their role in the modulation of pain response in the central nervous system. Curr Neuropharmacol 16(2):210-221

81. Ji G, Neugebauer $V$ (2019) Contribution of corticotropin-releasing factor receptor 1 (CRF1) to serotonin receptor 5-HTR function in amygdala neurons in a neuropathic pain model. Int J Mol Sci 20(18):4380

82. Ji G, Zhang W, Mahimainathan L, Narasimhan M, Kiritoshi T, Fan X, Wang J, Green TA, Neugebauer V (2017) 5-HT receptor knockdown in the amygdala inhibits neuropathic-pain-related plasticity and behaviors. J Neurosci 37(6): 1378-1393

83. Yano JM, Yu K, Donaldson GP, Shastri GG, Ann P, Ma L, Nagler CR, Ismagilov RF, Mazmanian SK, Hsiao EY (2015) Indigenous bacteria from the gut microbiota regulate host serotonin biosynthesis. Cell 161(2):264-276

84. Clapham DE (2003) TRP channels as cellular sensors. Nature 426(6966):517524

85. Montell C, Birnbaumer L, Flockerzi V (2002) The TRP channels, a remarkably functional family. Cell 108(5):595-598

86. Corey DP (2003) New TRP channels in hearing and mechanosensation. Neuron 39(4):585-588

87. Knowlton WM, Daniels RL, Palkar R, McCoy DD, McKemy DD (2011) Pharmacological blockade of TRPM8 ion channels alters cold and cold pain responses in mice. PLOS ONE 6(9):e25894

88. Ji G, Zhou S, Carlton SM (2008) Intact Adelta-fibers up-regulate transient receptor potential $\mathrm{A} 1$ and contribute to cold hypersensitivity in neuropathic rats. Neuroscience 154(3):1054-1066

89. del Camino D, Murphy S, Heiry M, Barrett LB, Earley TJ, Cook CA, Petrus MJ, Zhao M, D'Amours M, Deering N et al (2010) TRPA1 contributes to cold hypersensitivity. J Neurosci 30(45):15165-15174

90. Chen J, Joshi SK, DiDomenico S, Perner RJ, Mikusa JP, Gauvin DM, Segreti JA, Han P, Zhang X-F, Niforatos W et al (2011) Selective blockade of TRPA1 channel attenuates pathological pain without altering noxious cold sensation or body temperature regulation. Pain 152(5):1165-1172

91. Descoeur J, Pereira V, Pizzoccaro A, Francois A, Ling B, Maffre V, Couette B, Busserolles J, Courteix C, Noel J et al (2011) Oxaliplatin-induced cold hypersensitivity is due to remodelling of ion channel expression in nociceptors. EMBO Mol Med 3(5):266-278

92. Marwaha L, Bansal Y, Singh R, Saroj P, Bhandari R, Kuhad A (2016) TRP channels: potential drug target for neuropathic pain. Inflammopharmacology 24(6):305-317

93. Hong S, Wiley JW (2005) Early painful diabetic neuropathy is associated with differential changes in the expression and function of vanilloid receptor 1. J Biol Chem 280(1):618-627

94. Ferraz CCR, Henry MA, Hargreaves KM, Diogenes A (2011) Lipopolysaccharide from Porphyromonas gingivalis sensitizes capsaicinsensitive nociceptors. J Endod 37(1):45-48

95. Cenac N, Altier C, Motta J-P, d'Aldebert E, Galeano S, Zamponi GW, Vergnolle N (2010) Potentiation of TRPV4 signalling by histamine and serotonin: an important mechanism for visceral hypersensitivity. Gut 59(4) 481-488

96. Gwak YS, Kang J, Unabia GC, Hulsebosch CE (2012) Spatial and temporal activation of spinal glial cells: role of gliopathy in central neuropathic pain following spinal cord injury in rats. Exp Neurol 234(2):362-372
97. Hains BC, Waxman SG (2006) Activated microglia contribute to the maintenance of chronic pain after spinal cord injury. J Neurosci 26(16): 4308-4317

98. Hu L-Y, Zhou Y, Cui W-O, Hu X-M, Du L-X, Mi W-L, Chu Y-X, Wu G-C, Wang Y-Q, Mao-Ying Q-L (2018) Triggering receptor expressed on myeloid cells 2 (TREM2) dependent microglial activation promotes cisplatin-induced peripheral neuropathy in mice. Brain Behav Immun 68:132-145

99. Suter MR, Wen Y-R, Decosterd I, Ji R-R (2007) Do glial cells control pain? Neuron Glia Biol 3(3):255-268

100. Chen G, Zhang Y-Q, Qadri YJ, Serhan CN, Ji R-R (2018) Microglia in pain: detrimental and protective roles in pathogenesis and resolution of pain. Neuron 100(6):1292-1311

101. Ji R-R, Xu Z-Z, Gao Y-J (2014) Emerging targets in neuroinflammation-driven chronic pain. Nat Rev Drug Discov 13(7):533-548

102. Inoue K, Tsuda M (2018) Microglia in neuropathic pain: cellular and molecular mechanisms and therapeutic potential. Nat Rev Neurosci 19(3): 138-152

103. Erny $D$, Hrabě de Angelis AL, Jaitin D, Wieghofer $P$, Staszewski $O$, David $E$, Keren-Shaul H, Mahlakoiv T, Jakobshagen K, Buch T et al (2015) Host microbiota constantly control maturation and function of microglia in the CNS. Nat Neurosci 18(7):965-977

104. Herculano-Houzel S (2014) The glia/neuron ratio: how it varies uniformly across brain structures and species and what that means for brain physiology and evolution. Glia 62(9):1377-1391

105. Verkhratsky A, Sofroniew MV, Messing A, deLanerolle NC, Rempe D, Rodríguez JJ, Nedergaard M (2012) Neurological diseases as primary gliopathies: a reassessment of neurocentrism. ASN Neuro 4(3):e00082

106. Simard M, Nedergaard M (2004) The neurobiology of glia in the context of water and ion homeostasis. Neuroscience 129(4):877-896

107. Cui Y, Yang Y, Ni Z, Dong Y, Cai G, Foncelle A, Ma S, Sang K, Tang S, Li Y et al (2018) Astroglial Kir4.1 in the lateral habenula drives neuronal bursts in depression. Nature 554(7692):323-327

108. Tsuda M, Kohro Y, Yano T, Tsujikawa T, Kitano J, Tozaki-Saitoh H, Koyanagi S, Ohdo S, Ji R-R, Salter MW et al (2011) JAK-STAT3 pathway regulates spinal astrocyte proliferation and neuropathic pain maintenance in rats. Brain 134(Pt 4):1127-1139

109. Ji RR, Donnelly CR, Nedergaard M (2019) Astrocytes in chronic pain and itch Nat Rev Neurosci 20(11):667-685

110. Menetski J, Mistry S, Lu M, Mudgett JS, Ransohoff RM, Demartino JA, Macintyre DE, Abbadie C (2007) Mice overexpressing chemokine ligand 2 (CCL2) in astrocytes display enhanced nociceptive responses. Neuroscience 149(3):706-714

111. Nam Y, Kim J-H, Kim J-H, Jha MK, Jung JY, Lee M-G, Choi I-S, Jang I-S, Lim DG, Hwang S-H et al (2016) Reversible induction of pain hypersensitivity following optogenetic stimulation of spinal astrocytes. Cell Rep 17(11):30493061

112. Haydon PG, Carmignoto G (2006) Astrocyte control of synaptic transmission and neurovascular coupling. Physiol Rev 86(3):1009-1031

113. Zhang Y, Huang R, Cheng M, Wang L, Chao J, Li J, Zheng P, Xie P, Zhang Z, Yao H (2019) Gut microbiota from NLRP3-deficient mice ameliorates depressive-like behaviors by regulating astrocyte dysfunction via circHIPK2 Microbiome 7(1):116

114. Huang R, Zhang Y, Han B, Bai Y, Zhou R, Gan G, Chao J, Hu G, Yao H (2017) Circular RNA HIPK2 regulates astrocyte activation via cooperation of autophagy and ER stress by targeting MIR124-2HG. Autophagy 13(10):1722-1741

115. Rothhammer V, Mascanfroni ID, Bunse L, Takenaka MC, Kenison JE, Mayo L, Chao C-C, Patel B, Yan R, Blain M et al (2016) Type I interferons and microbial metabolites of tryptophan modulate astrocyte activity and central nervous system inflammation via the aryl hydrocarbon receptor. Nat Med 22(6):586-597

116. Rothhammer V, Borucki DM, Tjon EC, Takenaka MC, Chao C-C, ArduraFabregat A, de Lima KA, Gutiérrez-Vázquez C, Hewson P, Staszewski O et al (2018) Microglial control of astrocytes in response to microbial metabolites. Nature 557(7707):724-728

117. Junier MP (2000) What role(s) for TGFalpha in the central nervous system? Prog Neurobiol 62(5):443-473

118. White RE, Yin FQ, Jakeman LB (2008) TGF-alpha increases astrocyte invasion and promotes axonal growth into the lesion following spinal cord injury in mice. Exp Neurol 214(1):10-24

119. Kigerl KA, Hall JCE, Wang L, Mo X, Yu Z, Popovich PG (2016) Gut dysbiosis impairs recovery after spinal cord injury. J Exp Med 213(12):2603-2620 
120. Morales-Soto W, Gulbransen BD (2019) Enteric glia: a new player in abdominal pain. Cell Mol Gastroenterol Hepatol 7(2):433-445

121. Kabouridis PS, Lasrado R, McCallum S, Chng SH, Snippert HJ, Clevers H, Pettersson S, Pachnis V (2015) The gut microbiota keeps enteric glial cells on the move; prospective roles of the gut epithelium and immune system Gut Microbes 6(6):398-403

122. Nicholson JK, Holmes E, Kinross J, Burcelin R, Gibson G, Jia W, Pettersson S (2012) Host-gut microbiota metabolic interactions. Science 336(6086):12621267

123. Kabouridis PS, Lasrado R, McCallum S, Chng SH, Snippert HJ, Clevers H, Pettersson S, Pachnis V (2015) Microbiota controls the homeostasis of glial cells in the gut lamina propria. Neuron 85(2):289-295

124. Gribble FM, Reimann F (2016) Enteroendocrine cells: chemosensors in the intestinal epithelium. Annu Rev Physiol 78:277-299

125. Yang Y, Cui X, Chen Y, Wang Y, Li X, Lin L, Zhang H (2014) Exendin-4, an analogue of glucagon-like peptide-1, attenuates hyperalgesia through serotonergic pathways in rats with neonatal colonic sensitivity. J Physiol Pharmacol 65(3):349-357

126. Xu M, Wu H-Y, Liu H, Gong N, Wang Y-R, Wang Y-X (2017) Morroniside, a secoiridoid glycoside from Cornus officinalis, attenuates neuropathic pain by activation of spinal glucagon-like peptide-1 receptors. Br J Pharmacol 174(7):580-590

127. Holzer P, Reichmann F, Farzi A (2012) Neuropeptide $Y$, peptide $Y Y$ and pancreatic polypeptide in the gut-brain axis. Neuropeptides 46(6):261-274

128. Hassan AM, Jain P, Mayerhofer R, Fröhlich EE, Farzi A, Reichmann F, Herzog H, Holzer P (2017) Visceral hyperalgesia caused by peptide $Y Y$ deletion and Y2 receptor antagonism. Sci Rep 7:40968

129. Bohórquez DV, Shahid RA, Erdmann A, Kreger AM, Wang Y, Calakos N, Wang F, Liddle RA (2015) Neuroepithelial circuit formed by innervation of sensory enteroendocrine cells. J Clin Invest 125(2):782-786

130. Banerjee S, Sindberg G, Wang F, Meng J, Sharma U, Zhang L, Dauer P, Chen C, Dalluge J, Johnson T et al (2016) Opioid-induced gut microbial disruption and bile dysregulation leads to gut barrier compromise and sustained systemic inflammation. Mucosal Immunol 9(6):1418-1428

131. Lieu T, Jayaweera G, Zhao P, Poole DP, Jensen D, Grace M, Mclntyre P, Bron R, Wilson YM, Krappitz M et al (2014) The bile acid receptor TGR5 activates the TRPA1 channel to induce itch in mice. Gastroenterology 147(6):14171428

132. Alemi F, Kwon E, Poole DP, Lieu T, Lyo V, Cattaruzza F, Cevikbas F, Steinhoff M, Nassini R, Materazzi S et al (2013) The TGR5 receptor mediates bile acidinduced itch and analgesia. J Clin Invest 123(4):1513-1530

133. Mozaffarian D, Hao T, Rimm EB, Willett WC, Hu FB (2011) Changes in diet and lifestyle and long-term weight gain in women and men. N Engl J Med 364(25):2392-2404

134. Tong X, Dong JY, Wu ZW, Li W, Qin LQ (2011) Dairy consumption and risk of type 2 diabetes mellitus: a meta-analysis of cohort studies. Eur J Clin Nutr 65(9):1027-1031

135. Pusceddu MM, Gareau MG (2018) Visceral pain: gut microbiota, a new hope? J Biomed Sci 25(1):73

136. Eutamene H, Lamine F, Chabo C, Theodorou V, Rochat F, Bergonzelli GE, Corthésy-Theulaz I, Fioramonti J, Bueno L (2007) Synergy between Lactobacillus paracasei and its bacterial products to counteract stressinduced gut permeability and sensitivity increase in rats. J Nutr 137(8):19011907

137. Distrutti E, Cipriani S, Mencarelli A, Renga B, Fiorucci S (2013) Probiotics VSL\#3 protect against development of visceral pain in murine model of irritable bowel syndrome. PLoS ONE 8(5):e63893

138. Paramsothy S, Kamm MA, Kaakoush NO, Walsh AJ, van den Bogaerde J, Samuel D, Leong RWL, Connor S, Ng W, Paramsothy R et al (2017) Multidonor intensive faecal microbiota transplantation for active ulcerative colitis: a randomised placebo-controlled trial. Lancet 389(10075):1218-1228

139. Zuo T, Wong SH, Lam K, Lui R, Cheung K, Tang W, Ching JYL, Chan PKS, Chan MCW, Wu JCY et al (2018) Bacteriophage transfer during faecal microbiota transplantation in infection is associated with treatment outcome. Gut 67(4):634-643

140. Thurm T, Ablin JN, Buskila D, Maharshak N (2017) Fecal microbiota transplantation for fibromyalgia: a case report and review of the literature. Open J Gastroenterol 07(04):131-139

141. Weingarden AR, Chen C, Bobr A, Yao D, Lu Y, Nelson VM, Sadowsky MJ, Khoruts A (2014) Microbiota transplantation restores normal fecal bile acid composition in recurrent Clostridium difficile infection. Am J Physio Gastrointest Liver Physiol 306(4):G310-G319

142. Khoruts A, Sadowsky MJ (2016) Understanding the mechanisms of faecal microbiota transplantation. Nat Rev Gastroenterol Hepatol 13(9):508-516

143. Zhou S-Y, Gillilland M, Wu X, Leelasinjaroen P, Zhang G, Zhou H, Ye B, Lu Y, Owyang C (2018) FODMAP diet modulates visceral nociception by lipopolysaccharide-mediated intestinal inflammation and barrier dysfunction. J Clin Invest 128(1):267-280

144. Staudacher HM, Whelan K (2017) The low FODMAP diet: recent advances in understanding its mechanisms and efficacy in IBS. Gut 66(8):1517-1527

145. Bourdu S, Dapoigny M, Chapuy E, Artigue F, Vasson M-P, Dechelotte P, Bommelaer G, Eschalier A, Ardid D (2005) Rectal instillation of butyrate provides a novel clinically relevant model of noninflammatory colonic hypersensitivity in rats. Gastroenterology 128(7):1996-2008

146. Halmos EP, Christophersen CT, Bird AR, Shepherd SJ, Gibson PR, Muir JG (2015) Diets that differ in their FODMAP content alter the colonic luminal microenvironment. Gut 64(1):93-100

147. Staudacher HM, Lomer MCE, Anderson JL, Barrett JS, Muir JG, Irving PM, Whelan K (2012) Fermentable carbohydrate restriction reduces luminal bifidobacteria and gastrointestinal symptoms in patients with irritable bowel syndrome. J Nutr 142(8):1510-1518

148. Skalli S, Muller M, Pradines S, Halimi S, Wion-Barbot N (2012) Vitamin D deficiency and peripheral diabetic neuropathy. Eur J Intern Med 23(2):e67e68

149. Riccio P, Rossano R (2018) Diet, gut microbiota, and vitamins $D+A$ in multiple sclerosis. Neurotherapeutics 15(1):75-91

150. Ghareghani M, Reiter RJ, Zibara K, Farhadi N (2018) Latitude, vitamin D, melatonin, and gut microbiota act in concert to initiate multiple sclerosis: a new mechanistic pathway. Front Immunol 9:2484

151. Kanhere M, Chassaing B, Gewirtz AT, Tangpricha V (2018) Role of vitamin D on gut microbiota in cystic fibrosis. J Steroid Biochem Mol Biol 175:82-87

152. Sun J (2017) The role of vitamin D and vitamin D receptors in colon cancer. Clin Transl Gastroenterol 8(6):e103

153. Sari A, Akdogan Altun Z, Arifoglu Karaman C, Bilir Kaya B, Durmus B (2020) Does vitamin $\mathrm{D}$ affect diabetic neuropathic pain and balance? J Pain Res 13: 171-179

154. Bashir M, Prietl B, Tauschmann M, Mautner SI, Kump PK, Treiber G, Wurm P, Gorkiewicz G, Högenauer C, Pieber TR (2016) Effects of high doses of vitamin D3 on mucosa-associated gut microbiome vary between regions of the human gastrointestinal tract. Eur J Nutr 55(4):1479-1489

155. Banafshe HR, Khoshnoud MJ, Abed A, Saghazadeh M, Mesdaghinia A (2019) Vitamin D supplementation attenuates the behavioral scores of neuropathic pain in rats. Nutr Neurosci 22(10):700-705

156. Poisbeau P, Aouad M, Gazzo G, Lacaud A, Kemmel V, Landel V, Lelievre V, Feron F (2019) Cholecalciferol (Vitamin D) reduces rat neuropathic pain by modulating opioid signaling. Mol Neurobiol 56(10):7208-7221

157. Foster JA, McVey Neufeld K-A (2013) Gut-brain axis: how the microbiome influences anxiety and depression. Trends Neurosci 36(5):305-312

158. Park AJ, Collins J, Blennerhassett PA, Ghia JE, Verdu EF, Bercik P, Collins SM (2013) Altered colonic function and microbiota profile in a mouse model of chronic depression. Neurogastroenterol Motil 25(9):733-e575

159. O'Mahony SM, Marchesi JR, Scully P, Codling C, Ceolho A-M, Quigley EMM, Cryan JF, Dinan TG (2009) Early life stress alters behavior, immunity, and microbiota in rats: implications for irritable bowel syndrome and psychiatric illnesses. Biol Psychiatry 65(3):263-267

160. Diaz Heijtz R, Wang S, Anuar F, Qian Y, Björkholm B, Samuelsson A, Hibberd ML, Forssberg H, Pettersson S (2011) Normal gut microbiota modulates brain development and behavior. Proc Natl Acad Sci USA 108(7):3047-3052

161. Clarke G, Grenham S, Scully P, Fitzgerald P, Moloney RD, Shanahan F, Dinan TG, Cryan JF (2013) The microbiome-gut-brain axis during early life regulates the hippocampal serotonergic system in a sex-dependent manner. Mol Psychiatry 18(6):666-673

162. Bruce-Keller AJ, Salbaum JM, Luo M, Blanchard E, Taylor CM, Welsh DA, Berthoud H-R (2015) Obese-type gut microbiota induce neurobehavioral changes in the absence of obesity. Biol Psychiatry 77(7):607-615

163. Bercik P, Denou E, Collins J, Jackson W, Lu J, Jury J, Deng Y, Blennerhassett P, Macri J, McCoy KD et al (2011) The intestinal microbiota affect central levels of brain-derived neurotropic factor and behavior in mice. Gastroenterology 141(2):599-609

164. Michel L, Prat A (2016) One more role for the gut: microbiota and blood brain barrier. Ann Transl Med 4(1):15 
165. Braniste V, Al-Asmakh M, Kowal C, Anuar F, Abbaspour A, Tóth M, Korecka A, Bakocevic N, Ng LG, Guan NL et al (2014) The gut microbiota influences blood-brain barrier permeability in mice. Sci Transl Med 6(263):263ra158

166. Chen H, Lamer TJ, Rho RH, Marshall KA, Sitzman BT, Ghazi SM, Brewer RP (2004) Contemporary management of neuropathic pain for the primary care physician. Mayo Clin Proc 79(12):1533-1545

167. Dworkin RH, Backonja M, Rowbotham MC, Allen RR, Argoff CR, Bennett GJ Bushnell MC, Farrar JT, Galer BS, Haythornthwaite JA et al (2003) Advances in neuropathic pain: diagnosis, mechanisms, and treatment recommendations. Arch Neurol 60(11):1524-1534

168. Gilron I, Baron R, Jensen T (2015) Neuropathic pain: principles of diagnosis and treatment. Mayo Clin Proc 90(4):532-545

169. Browne HP, Forster SC, Anonye BO, Kumar N, Neville BA, Stares MD, Goulding D, Lawley TD (2016) Culturing of 'unculturable' human microbiota reveals novel taxa and extensive sporulation. Nature 533(7604):543-546

170. de Groot PF, Frissen MN, de Clercq NC, Nieuwdorp M (2017) Fecal microbiota transplantation in metabolic syndrome: History, present and future. Gut Microbes 8(3):253-267

171. Gupta A, Khanna S (2017) Fecal microbiota transplantation. JAMA 318(1):102

\section{Publisher's Note}

Springer Nature remains neutral with regard to jurisdictional claims in published maps and institutional affiliations.

Ready to submit your research? Choose BMC and benefit from:

- fast, convenient online submission

- thorough peer review by experienced researchers in your field

- rapid publication on acceptance

- support for research data, including large and complex data types

- gold Open Access which fosters wider collaboration and increased citations

- maximum visibility for your research: over $100 \mathrm{M}$ website views per year

At BMC, research is always in progress.

Learn more biomedcentral.com/submissions 